\title{
КОНСТИТУЦИОННО-ПРАВОВАЯ ОТВЕТСТВЕННОСТЬ ФИЗИЧЕСКИХ ЛИЦ С ОСОБЫМ СТАТУСОМ ПРЕБЫВАНИЯ НА ТЕРРИТОРИИ РФ
}

\begin{abstract}
Аннотация. Ответственность физических лиц является мало исследованным объектом в теории конституционной ответственности. К числу лиц с особым конституционно-правовым статусом пребывания на территории РФ следует относить всех тех субъектов, которые не обладают гражданством РФ как основополагающим правом нахождения на ее территории; а также вынужденных переселенцев, то есть лии, вынужденных покинуть привычное место проживания. Вопросы, связанные с ответственностью данных лиц, вытекающей из их конституционно-правового статуса, обосновывают необходимость рассмотрения соответствующих правовых положений. Для осуществления поставленной цели были выбраны такие методы познания как формально-юридический, системный; метод анализа, метод сопоставления. В результате исследования были определены субъекты со специальным и предварительным конституционно-правовым статусом пребывания на территории РФ или в определенной ее части; основания ответственности и способ их отделения от оснований применения мер защиты; выявлены пробелы в закреплении ряда оснований ответственности; проанализированы позиции ученых относительно признания либо непризнания тех или иных мер в качестве конституционно-правовых санкций, предложен и обоснован собственный вариант конституционно-правовых санкций, которые могут быть применены в отношении физических лиц с выше обозначенным статусом.
\end{abstract}

Ключевые слова: иностранные граждане, лица без гражданства, беженцы, вынужденные переселенцы, конституционно-правовая ответственность, особый конституционно-правовой статус, конституционно-правовые санкции, основания конституционной ответственности, депортация, административное выдворение.

Abstract. The responsibility of individuals is a poorly studied object of the constitutional responsibility theory. Among individuals with a special constitutional status of stay in the Russian Federation, should be reckoned all individuals, who don't possess the nationality of the Russian Federation as a basic right for stay on its territory, and displaced persons. The issues of responsibility of such individuals, resulting from their constitutional status, substantiate the necessity to consider the related legal provisions. To achieve this goal, the author applies the formal-legal and system methods, the methods of analysis and comparison. The author defines individuals with the special and the preliminary constitutional and legal status of stay in the Russian Federation or its part; the grounds of responsibility and the way of their distinguishing from the grounds of application of protective measures; reveals the gaps in legal consolidation of some grounds of responsibility; analyzes the scholars' positions on recognition or non-recognition of any measures as constitutional sanctions; offers and substantiates her own variant of constitutional sanctions, which can be imposed on individuals with a special status.

Key words: constitutional and legal sanctions, displaced persons, constitutional and legal responsibility, refugees, special constitutional status, stateless persons, foreign citizens, grounds of constitutional responsibility, deportation, administrative expulsion.

И ностранные граждане, лица без гражданства обладают определенным конституционно-правовым статусом, вытекающим из совокупности их прав и обязанностей, предоставляемых и налагаемых Российской Федерацией в связи с нахождением на ее территории. По отношению к таким гражданам принят националь- ный режим с исключениями, которые касаются условий нахождения на ее территории, получения политических прав и социальных прав (перечень таких прав и их объем определяется на основании международного договора, если такой заключен). То есть соответствующая группа физических лиц обладает пусть и ограниченным по сравнению с 
гражданами РФ статусом, однако также состоящим из трех основных элементов - прав, обязанностей и ответственности.

Особенность правового статуса субъекта ответственности. Конституционно-правовая ответственность граждан преимущественно связана с поражением в ряде конституционных прав, в основном социально-политического характера, наступающим вследствие совершения конституционного правонарушения.

Но так как в большинстве своем иностранные граждане и лица без гражданства политическим правами не обладают, а социальными - только в определенной части, общим условием определения их правового статуса является та или иная форма пребывания на территории РФ, в частности получение вида на жительство (ст. 8 Федерального закона о правовом положении иностранных граждан в РФ [1]), приобретение статуса беженца (ст. 8 Федерального закона о беженцах [2]), то, соответственно, можно сделать вывод, что санкционный порядок в отношении этих лиц определяется, главным образом, посредством аннулирования их права пребывания (проживания) на территории РФ.

Аналогичный порядок можно заметить и в отношении граждан РФ, вынужденных уехать из постоянного места жительства в силу экстренных обстоятельств, наличие которых дает им возможность приобрести статус вынужденного переселенца, то есть ряд дополнительных прав и обязанностей, и таким образом установить отличные от иных граждан страны условия взаимосвязи с государством (п. 2 ст. 1 Федерального закона о вынужденных переселенцах [3]). А потому и иностранных граждан, лиц без гражданства, и вынужденных переселенцев можно признать в качестве лиц одной категории - физических лиц, обладающих особым конституционным статусом, связанным с той или иной формой пребывания на территории РФ или в определенной ее части.

В отношении лиц, стремящихся получить специальный конституционно-правовой статус пребывания (проживания), также установлены требования соблюдения закона и пребывания на территории РФ или в определенной ее части, и их статус можно назвать предварительным (временно-разрешительным) конституционно-правовым статусом, в частности, статус лица, обратившегося с ходатайством о признании беженцем; статус лица, получившего свидетельство о регистрации ходатайства о признании вынужденным переселенцем; статус лица, выразившего желание приобрести гражданство РФ в порядке признания или приема в гражданство РФ.

Таким образом, конституционно-правовые статусы, связанные с той или иной формой пребывания на территории РФ или в определенной ее ча- сти, следует разделить на два вида: специальный конституционно-правовой статус и предварительный конституционно-правовой статус.

Вид налагаемой ответственности. В научной литературе вопрос об определении вида ответственности физических лиц, в том числе лиц с особым статусом пребывания на территории РФ или в ее части, носит дискуссионный характер. По мнению одних ученых, физических лиц следует считать обладателями конституционного статуса, субъектами конституционного правонарушения [4, с. $71 ; 5$, с. $280 ; 6$, с. $159 ; 7$, с. $19-21 ; 8$, с. $21 ; 9$, с. 24$]$; с точки зрения других - обозначаемый статус носит административно-правовой характер [10, с. 13-14].

Разрешение вопроса, на наш взгляд, зависит от того, какой набор прав и обязанностей приобретает соответствующее лицо, конституционного или административного характера и, соответственно, вступает в отношения, регулируемые нормами конституционного или административного права.

Приобретение обозначенного статуса теми или иными лицами устанавливает их взаимодействие с рядом административных органов, в частности с территориальным органом исполнительной власти в сфере миграции. Наличие отношений, связанных с получением, продлением определенного статуса, порождает в отношении лица набор определенных обязанностей, охраняемых нормами административного права и, соответственно, наделяющими его административно-правовым статусом, но лишь в части взаимоотношений с соответствующими административными органами.

Присвоение физическому лицу особого статуса пребывания на территории РФ влечет установление отношений с государством (в данном случае с Российской Федерацией), влекущих изменение общего, конституционно-правового, положения лица, определяет его публично-правовой статус; соответственно, как присвоение, так и ограничение, лишение данного статуса подразумевает под собой конституционно-правовое регулирование и применение в случае совершения конституционного правонарушения конституционных (то есть учреждаемых конституционным правом) санкций.

Основания ответственности. Основания аннулирования присвоенного статуса можно признать основаниями применения ответственности, но лишь в том случае, если они указывают на виновное поведение лица. Безвиновное поведение влечет применение мер защиты.

Так, А. А. Кондрашев к основаниям применения мер ответственности в виде аннулирования разрешения на временное проживание иностранных граждан относит следующие положения Федерального закона об иностранных гражданах в РФ: иностранный гражданин выступает за насиль- 


\section{Административное и муниципальное право 11 (107) • 2016}

ственное изменение конституционного строя РФ, иными действиями создает угрозу безопасности РФ или граждан РФ; финансирует, планирует террористические (экстремистские) акты, оказывает содействие в совершение таких актов или совершает их, а равно иными действиями поддерживает террористическую (экстремистскую) деятельность; предоставил поддельные или подложные документы либо сообщил о себе заведомо ложные сведения; неоднократно (два раза и более) в течение одного года привлекался к административной ответственности за нарушение законодательства РФ в области обеспечения режима пребывания (проживания) иностранных граждан в РФ [4, с. 72].

Иные основания, по мнению ученого, санкциями не являются; в частности, если иностранный гражданин в течение 5 лет, предшествовавших до подачи заявления о выдаче разрешения на временное проживание, подвергался административному выдворению за пределы РФ либо депортации; осужден вступившим в законную силу приговором суда за совершение тяжкого либо особо тяжкого преступления либо преступления, рецидив которого признан опасным; имеет непогашенную или неснятую судимость за совершение тяжкого или особо тяжкого преступления на территории РФ либо за ее пределами, признаваемого таковым в соответствии с федеральным законом; не может представить доказательств возможности содержать себя и членов своей семьи в РФ в пределах прожиточного минимума, не прибегая к помощи государства, за исключением случая, если иностранный гражданин признан нетрудоспособным; по истечении трех лет со дня въезда не имеет в РФ жилого помещения на основаниях, предусмотренных законодательством РФ; выехал из РФ в иностранное государство для постоянного проживания; находится за пределами РФ более шести месяцев; заключил брак с гражданином РФ, послуживший основанием для получения разрешения на временное проживание, и этот брак признан судом недействительным; является больным наркоманией, либо не имеет сертификата об отсутствии у него заболевания, вызванного вирусом иммунодефицита человека (ВИЧ-инфекции), либо страдает одним из инфекционных заболеваний, которые представляют опасность для окружающих [4, с. 72].

А. М. Цалиев и М. С. Басиев полагают, что к числу обеспеченных мерами конституционно-правовой ответственности можно признать лишь основания, указанные в подпунктах 1, 2, 4-7 части и часть 1.2 ст. 7 Федерального закона о правовом положении иностранных граждан в РФ [6, с. 164], то есть также выпуская ряд оснований, представленных законом; при этом не указывая, что явилось критерием такого разделения.
Как представляется, невключенные учеными основания также следует признать основаниями ответственности, за исключением пункта, когда иностранный гражданин не обладает средствами для существования или жилым помещением не по своей вине, и пункта, касающегося наличия у иностранного гражданина соответствующего заболевания, кроме основания, когда иностранным гражданином не предоставлен сертификат об отсутствии у него ВИЧ-инфекции.

Наличие у лица заболевания, представляющего опасность для окружающих, либо препятствий для обеспечения средствами существования себя и членов своей семьи, названные в качестве основания для аннулирования либо отказа в разрешении на получение временного разрешения на проживание, служат мерой защиты граждан, проживающих на территории страны, в том числе посредством защиты их от возложения дополнительных обязательств по социальному обеспечению лиц, находящихся на ее территории, но не обладающих российским гражданством. Во всех остальных случаях имеется виновное поведение лица, мешающее ему получить либо продлить право на временное проживание.

Таким образом, к числу оснований применения конституционно-правовой ответственности в виде лишения права на временное проживание иностранному гражданину и лицу без гражданства можно отнести: подпункты 1-12 п. 1 ст. 7 (с учетом выше обозначенных исключений); пп. 13 п. 1 ст. 7 в части получения сертификата об отсутствии у него ВИЧинфекции; пп. 14 п. 1; п. 1.5 ст. 7 - за исключением того варианта, когда иностранный гражданин был ограничен в родительских правах не в связи с собственным виновным поведением; к числу оснований для аннулирования разрешения на временное проживание, выданное иностранному гражданину, признанному участником Государственной программы по оказанию содействия добровольного переселения в РФ соотечественников и членов их семей, - подп. 1-7, 10-11 п. 1 ст. 7 Федерального закона о правовом положении иностранных граждан в РФ.

К числу оснований применения ответственности следует отнести п. 1.2 ст. 7, где указывается, что разрешение на временное проживание иностранному гражданину и лицу без гражданства аннулируется в случае принятия в установленном порядке решения о нежелательности пребывания (проживания) в РФ или решения о неразрешении въезда в РФ иностранного гражданина и лица без гражданства. Основания принятия такого решения предусмотрены Федеральным законом о порядке выезда из РФ и въезда в РФ [11], в частности, пребывание иностранного гражданина или лица без гражданства на территории РФ нежелательно, если это создает реальную угрозу обороноспособ- 
ности или безопасности государства, либо общественному порядку, либо здоровью населения, в целях защиты основ конституционного строя, нравственности, прав и законных интересов других лиц (абз. 4 ст. 25.10). Однако данное положение вовсе не указывает на обязательность наличия вины лица, в отношении которого может приниматься соответствующее решение, например, лицо может иметь гражданство государства, с которым возникает какая-то конфликтная ситуация; таким образом, лишь виновные поступки лица, влекущие угрозу защищаемым субъектам, можно считать правонарушением и, соответственно, основанием применения ответственности.

Аналогичную характеристику можно дать и основаниям, определяющим аннулирование вида на жительство, с некоторыми дополнениями для лиц, признанных носителями русского языка (ст. 9 Федерального закона о правовом положении иностранных граждан в РФ).

Однако среди оснований, допускающих лишение права на получение (сохранение) вида на жительство, не предусмотрено такое, как лишение или ограничение иностранного гражданина решением суда, вступившим в законную силу, родительских прав в отношении ребенка, состоящего в гражданстве РФ.

Следует, на наш взгляд, согласиться с А. А. Кондрашевым в том, что необходимо унифицировать основания применения мер ответственности в отношении всех лиц, обладающих особым конституционно-правовым положением (иностранцев, беженцев, вынужденных переселенцев) [4, с. 75], по крайней мере, в отношении установления общих запретов и равных обязанностей.

Основаниями для лишения лица статуса беженца являются: осуждение за совершение преступления на территории РФ, сообщение заведомо ложных сведений либо предъявление фальшивых документов, послуживших основанием для признания беженцем, либо допущение иного нарушения положений Федерального закона о беженцах; привлечение к административной ответственности за совершение административного правонарушения, связанного с незаконным оборотом наркотических средств или психотропных веществ и их прекурсоров, растений, содержащих наркотические средства или психотропные вещества либо их прекурсоры, а также их частей, содержащих наркотические средства или психотропные вещества либо их прекурсоры (пп. 1-3 п. 2 ст. 9 Федерального закона о беженцах).

Основанием для лишения статуса вынужденного переселенца названо одно - умышленное сообщение ложных сведений или предъявление заведомо фальшивых документов, послуживших основанием для признания вынужденным переселенцем (пп. 2 п. 3 ст. 9 Федерального закона о вынужденных переселенцах).

В отношении лиц, имеющих предварительный конституционно-правовой статус, установлен определенный объем прав и обязанностей (например, в ст. 6 Федерального закона о беженцах, ст. 4 Федерального закона о вынужденных переселенцах), однако не предусмотрены последствия нарушения соответствующих обязанностей и злоупотребления правами. Можно лишь предположить об учете нарушений федерального закона при принятии решения об удовлетворении направленного такими лицами ходатайства о получении специального конституционно-правового статуса.

Но подобное разрешение вопроса противоречит положениям законодательства, в частности, устанавливающим основания для отказа в праве на получение статуса вынужденного переселенца или беженца. Так, основаниями для отказа в праве на признание вынужденным переселенцем названы: совершение преступления против мира, человечности и другого тяжкого преступления, признаваемое таковым законодательством РФ, необращение без уважительных причин с ходатайством о признании вынужденным переселенцем в течение двенадцати месяцев со дня выбытия с места жительства; выезд с места жительства по экономическим причинам либо вследствие голода, эпидемии или чрезвычайных ситуаций (п. 1 ст. 2 Федерального закона о вынужденных переселенцах); первые два из предусмотренных оснований в силу присутствия элемента виновности в действиях лица, имеющего предварительный конституционно-правовой статус, можно отнести к основаниям конституционно-правовой ответственности.

Не определены, за очень редким исключением, меры ответственности за невыполнение обязанностей лицами, уже получившими специальный конституционно-правовой статус.

Так, вынужденный переселенец обязан соблюдать Конституцию РФ, установленный порядок проживания в центре временного размещения вынужденных переселенцев и жилом помещением фонда для временного поселения вынужденного переселенца; при перемене места жительства в пределах территории РФ встать на учет по новому месту жительства в территориальный орган федерального органа исполнительной власти, уполномоченный на осуществление функций по контролю и надзору в сфере миграции; проходить переучет в установленные сроки (п. 2 ст. 6 Федерального закона о вынужденных переселенцах). Правда, соблюдение Конституции РФ и законов общая для всех граждан и не граждан, находящихся на территории РФ, обязанность, а потому не может 


\section{Административное и муниципальное право 11 (107) • 2016}

являться специальной обязанностью вынужденного переселенца.

Между тем следовало бы за неисполнение закрепленных как за лицами, получившими специальный конституционно-правовой статус, так и за лицами, имеющими предварительный конституционно-правовой статус, обязанностей, злоупотребление предоставленными правами предусмотреть меры ответственности. Ими могут стать - лишение права, которым злоупотребило (не использовало по назначению) лицо, неисполнение, неоднократное неисполнение или ненадлежащее исполнение обязанности.

В частности, в соответствии с п. 3 ст. 6 Федерального закона о вынужденных переселенцах лицо может быть лишено права на проживание в жилом помещении фонда для временного поселения вынужденных переселенцев в случае, если он отсутствует там свыше шести месяцев без уважительных причин. То есть установлена санкция за определенный вид злоупотребления предоставленным правом. А должна иметь место ответственность за злоупотребление правом в любой форме. Например, за то, что лицо подселяет к себе лиц, не являющихся членами его семьи, разрушает предоставленное жилое помещение, нарушает порядок общежития и т. д.

Злоупотребление правом или неисполнение обязанности может рассматриваться как административное правонарушение либо конституционное в зависимости от применяемой санкции и свойственного для административного права закрепления основания и санкции в Кодексе РФ об административных правонарушениях.

Злостное (неоднократное и (или) существенно умаляющее права других лиц, законом установленный порядок) нарушение какой-либо обязанности или злоупотребление правом должно быть признано в качестве основания для лишения соответствующего статуса.

Санкции. Вопрос о санкциях ответственности за нарушение лицами, имеющими особый конституционно-правовой статус пребывания на территории РФ или в ее части, также не имеет однозначного определения как в законодательстве, так и в научной литературе.

При соотношении таких понятий как депортация и административное выдворение А. А. Кондрашев указывает на то, что эти санкции по своей природе и процедурным особенностям принадлежат к мерам административного принуждения, их основанием является нарушение публичной обязанности покинуть территорию РФ в связи с отсутствием законных оснований для продолжения пребывания на ней [4, с. 74].

С точки зрения А. М. Цалиева и М. С. Басиева, депортацию иностранных граждан следует при- знать мерой конституционно-правовой ответственности [6, с. 166, 162].

Ю. В. Паукова указывает на то, что депортация, как и административное выдворение, не может быть признана в качестве обеспечительного средства, так как наступает за невыполнение обязанности по добровольному выезду за пределы РФ, а потому является мерой административного пресечения и административно-восстановительной мерой (обе - меры административного принуждения); применяемыми как при наличии вины лица, так и при отсутствии ее [12, с. 181-185].

Нельзя не согласиться с тем, что и административное выдворение, и депортация выступают в качестве мер административного принуждения. Однако если административное принуждение названо в качестве меры административной ответственности (ст. 3.2 и 3.10 КоАП РФ), то депортация обозначена лишь как мера принудительного характера (п. 1 ст. 2 Федерального закона о правовом положении иностранных граждан в РФ). Вместе с тем основанием депортации является также неисполнение обязанности по добровольному выезду (сравним ст. 31 Федерального закона о правовом положении иностранных граждан в РФ и ст. 18.8 КоАП РФ), при наличии возможности осуществления такой обязанности (такой вывод можно сделать на основе соотношения положений об имеющейся обязанности выехать и условиях ее исполнения, обусловленных пп. 8 ст. 26 Федерального закона о порядке выезда из РФ и въезда в РФ); то есть, иначе говоря, виновного поведения лица, а, следовательно, сближает данную меру по своим правовым последствиям и основаниям (правонарушение) осуществления.

Здесь, правда, возникает другой вопрос: к какому виду правонарушений следует отнести неисполнение обязанности, предусмотренной Федеральным законом о правовом положении иностранных граждан в РФ? Думается, как и в случае с административным выдворением, основанием депортации также выступает административное правонарушение, заключающееся в неисполнение обязанности покинуть территорию РФ в установленные законом, в частности Федеральным законом о правовом положении иностранных граждан в РФ, сроки. По сути, это тоже самое правонарушение, что закреплено ч. 1.1 ст. 18.8 КоАП, - уклонение от выезда из РФ по истечении определенного срока пребывания.

Таким образом, депортацию можно признать частным случаем наказания за совершение административного правонарушения, совпадающей по имеющимся признакам с административным выдворением, если не считать одной особенности, закрепленной Кодексом РФ об административных правонарушениях. В статье 3.10 КоАП РФ адми- 
нистративное выдворение представлено в двух видах: как контролируемый самостоятельный выезд иностранных граждан и лиц без гражданства и как принудительный контролируемый выезд иностранных граждан и лиц без гражданства. То есть административное выдворение возможно в более легкой форме, чем депортация.

Для унификации мер, предназначенных в целях наказания за совершение административного правонарушения, связанного с нарушением порядка пребывания на территории РФ, было бы логично в Кодексе РФ об административных правонарушениях указать, что административное выдворение, имеющее принудительный характер, есть не что иное как депортация. В частности, в ст. 3.2 после слов административное выдворение в скобках указать «в том числе депортация» и в статье 3.10 относительно административного выдворения, заключающегося в принудительном контролируемом перемещении, также в скобках добавить слово «депортация».

Депортация не может являться конституционно-правовой санкцией, так как такой санкцией выступает лишение лица статуса, дающего право пребывания на территории РФ; не является реализационной мерой, так как выступает в качестве наказания за правонарушение, выраженное в форме неисполнения возникшей вследствие потери статуса обязанности; к тому же закрепленное в качестве административного правонарушения законом.

Нет однозначной позиции и в отношении таких мер как отклонение заявления о приобретении конституционно-правового статуса, связанного с правом пребывания (проживания) на территории РФ или в определенной ее части; отмена решения о предоставлении статуса. Например, по мнению одних исследователей, данного рода меры относятся к мерам конституционно-правовой ответственности [6, с. 162-169], с точки зрения других, - к мерам защиты [13, с. 253].

Если право на получение статуса гражданина РФ (иного конституционно-правового статуса, связанного с пребыванием на территории РФ или в определенной ее части) ограничено на основании совершения лицом виновного деяния, поступка, не совместимого с обладанием статусом, ходатайство на предоставление которого было заявлено, то отклонение соответствующего заявления можно рассматривать в качестве несоблюдения нормы закона, то есть не как санкцию, а как реализацию определенного законом положения. Санкцией же является лишение права на получение статуса в результате совершения правонарушения, одним из правовых последствий которого является лишение конституционного права. Совершение, в частности административного правонарушения, может выступать в качестве преюдиции наступле- ния конституционно-правовой ответственности в форме лишения определенного права. Неисполнение обязанности, злоупотребление правом лицом, имеющим предварительный конституционно-правовой статус, может выступать основанием для лишения права на получение специального конституционно-правового статуса с момента вынесения решения о совершении правонарушения, то есть юридического оформления соответствующего факта. По времени констатация факта правонарушения, последствием которого является лишение права на получение запрашиваемого конституционно-правового статуса, и отклонение заявления о получении такого статуса могут совпадать.

В результате следует признать, что отклонение заявления о возможности приема в гражданство РФ, о приеме в гражданство РФ и о восстановлении в гражданстве РФ (ч. 1 ст. 16 Федерального закона о гражданстве РФ [14]), отклонение ходатайства о признании вынужденным переселенцем (ст. 2 закона о вынужденных переселенцах) и т. д. выступают в качестве меры, направленной на реализацию положения закона, то есть техническим элементом в исполнении закона, в том числе в той его части, которая касается реализации обусловленной законом санкции.

Отмена решения о наделении соответствующим статусом в связи с виновными действиями лица является санкцией (лишением определенного блага).

Итак, конституционными санкциями, применяемыми к субъектам с особым конституционноправовым статусом, связанным с конкретной формой пребывания на территории РФ или в ее части, можно отнести:

1) лишение права лица, имеющего предварительный конституционно-правовой статус, на получение запрашиваемого конституционноправового статуса в связи с совершением деяния, не совместимого с получением соответствующего статуса;

2) лишение полученного конституционно-правового статуса в связи с совершением деяния, не совместимого с сохранением соответствующего статуса;

3) ограничение в правах, предоставляемых в соответствии с полученным конституционноправовым статусом.

Резюмируя вышеизложенное, следует отметить, что, во-первых, существует особый конституционно-правовой статус, связанный с определенной формой пребывания лица на территории РФ или в ее части; во-вторых, целесообразно выделять лиц со специальным конституционно-правовым статусом пребывания на территории РФ или в определенной ее части и с предварительным 


\section{Административное и муниципальное право 11 (107) • 2016}

конституционно-правовым статусом пребывания на территории РФ или в ее части; в-третьих, ответственность лиц с обозначенным конституционно-правовым статусом имеет конституционноправовой характер, наступает за виновное деяние, заключающееся в злоупотребление правом или не- исполнении, неоднократном неисполнении, ненадлежащем исполнении обязанности, регулируется нормами конституционного права и выражается посредством наложения конституционно-правовых санкций в виде лишения лица определенного права либо полученного статуса.

\section{Библиография:}

1. Федеральный закон от 25 июля 2002 года № 115-ФЗ «0 правовом положении иностранных граждан в РФ» (в ред. от 13.07.2015 № 230-Ф3) // СПС «КонсультантПлюс».

2. Федеральный закон от 19 февраля 1993 года № 4528-1 «О беженцах» (в ред. от 22.12.2014 № 446-Ф3) // СПС «КонсультантПлюс».

3. Федеральный закон от 19 февраля 1993 года № 4530-1 «О вынужденных переселенцах» (в ред. от 30.12 .2015 № 467-ФЗ) // СПС «КонсультантПлюс».

4. Кондрашев А. А. Конституционно-правовая ответственность иностранных граждан в Российской Федерации // Вестник Сибирского юридического института МВД России. 2010. № 2 (6). С. 71-75.

5. Пугачев А. Н. Конституционно-правовые санкции и их особенности // Проблемы укрепления законности и правопорядка: наука, практика, тенденции. 2009. № 1. С. 279-284.

6. Цалиев А. М., Басиев М. С. Конституционно-правовая ответственность: (современное состояние и проблемы совершенствования). М.; Владикавказ, 2009. 172 с.

7. Гороховцев О. В. Конституционная ответственность в Российской Федерации. Автореф. дис. ... канд. юрид. наук. М., 2008. 24 c.

8. Виноградов В. А. Конституционная ответственность: вопросы теории и правовое регулирование. М., 2000.287 с.

9. Басиев М. С. К вопросу о концепции конституционно-правовой ответственности // Право и политика. 2006 . № 9. C. $19-29$.

10. Малышев Е. А., Васильев А. Л. Некоторые особенности административно-правового статуса иностранного гражданина // Вестник Калининградского юридического института МВД России. 2009. № 1 (17). С. 12-15.

11. Федеральный закон от 15 августа 1996 года № 114-Ф3 «О порядке выезда из РФ и въезда в РФ» (в ред. от 30.12.2015 № 438-ФЗ) // СПС «КонсультантПлюс».

12. Паукова Ю. В. Депортация иностранных граждан и лиц без гражданства как мера административного принуждения // Правовая культура. 2012. № 2 (13). С. 181-185.

13. Мусаткина А. А. К вопросу о конституционных санкциях // Вектор науки Тольяттинского государственного университета. 2010. № 3. С. 252-254.

14. Федеральный закон от 31 мая 2002 года № 62-Ф3 «О гражданстве РФ» (в ред. от 31.12.2014 № 507-Ф3) // СПС «КонсультантПлюс».

\section{References (transliterated):}

1. Federal'nyi zakon ot 25 iyulya 2002 goda № $115-\mathrm{FZ}$ «O pravovom polozhenii inostrannykh grazhdan v RF» (v red. ot 13.07.2015 № 230-FZ) // SPS «Konsul'tantPlyus».

2. Federal'nyi zakon ot 19 fevralya 1993 goda № 4528-1 «0 bezhentsakh» (v red. ot 22.12.2014 № 446-FZ) // SPS «Konsul'tantPlyus».

3. Federal'nyi zakon ot 19 fevralya 1993 goda № 4530-1 «O vynuzhdennykh pereselentsakh» (v red. ot 30.12.2015 № 467FZ) // SPS «Konsul'tantPlyus».

4. Kondrashev A. A. Konstitutsionno-pravovaya otvetstvennost' inostrannykh grazhdan v Rossiiskoi Federatsii // Vestnik Sibirskogo yuridicheskogo instituta MVD Rossii. 2010. № 2 (6). S. 71-75.

5. Pugachev A. N. Konstitutsionno-pravovye sanktsii i ikh osobennosti // Problemy ukrepleniya zakonnosti i pravoporyadka: nauka, praktika, tendentsii. 2009. № 1. S. 279-284.

6. Tsaliev A. M., Basiev M. S. Konstitutsionno-pravovaya otvetstvennost': (sovremennoe sostoyanie i problemy sovershenstvovaniya). M.; Vladikavkaz, 2009.172 s.

7. Gorokhovtsev O. V. Konstitutsionnaya otvetstvennost' v Rossiiskoi Federatsii. Avtoref. dis. ... kand. yurid. nauk. M., 2008.24 s.

8. Vinogradov V. A. Konstitutsionnaya otvetstvennost': voprosy teorii i pravovoe regulirovanie. M., 2000.287 s.

9. Basiev M. S. K voprosu o kontseptsii konstitutsionno-pravovoi otvetstvennosti // Pravo i politika. 2006. № 9. S. 19-29.

10. Malyshev E. A., Vasil'ev A. L. Nekotorye osobennosti administrativno-pravovogo statusa inostrannogo grazhdanina // Vestnik Kaliningradskogo yuridicheskogo instituta MVD Rossii. 2009. № 1 (17). S. 12-15.

11. Federal'nyi zakon ot 15 avgusta 1996 goda № $114-\mathrm{FZ}$ «0 poryadke vyezda iz RF i v"ezda v RF» (v red. ot 30.12 .2015 № 438-FZ) // SPS «Konsul'tantPlyus».

12. Paukova Yu. V. Deportatsiya inostrannykh grazhdan i lits bez grazhdanstva kak mera administrativnogo prinuzhdeniya // Pravovaya kul'tura. 2012. № 2 (13). S. 181-185.

13. Musatkina A. A. K voprosu o konstitutsionnykh sanktsiyakh // Vektor nauki Tol'yattinskogo gosudarstvennogo universiteta. 2010. № 3. S. 252-254.

14. Federal'nyi zakon ot 31 maya 2002 goda № 62-FZ «O grazhdanstve RF» (v red. ot 31.12.2014 № 507-FZ) // SPS «Konsul'tantPlyus». 